ARTICLE

DOI: $10.1057 / \mathrm{s} 41599-018-0191-8$

\title{
Joining the Islamic State from France between 2014 and 2016: an observational follow-up study
}

Nicolas Campelo1,2,3, Laura Bouzar ${ }^{4}$, Alice Oppetit ${ }^{1}$, Hugues Pellerin ${ }^{1}$, Serge Hefez ${ }^{1}$, Guillaume Bronsard ${ }^{5,6,7}$, David Cohen ${ }^{1,8} \&$ Dounia Bouzar ${ }^{3}$

\begin{abstract}
A new model of radicalization has appeared in Western countries since the 2010s. However, few empirical data are available to interpret the profiles of European young people who have embraced radical Islamism. Mixing qualitative/quantitative approaches, the present study is the first to explore their motives for radicalization, as well as how characteristics at baseline predicted their status at follow-up (FU). In 2014-2015, 150 individuals (mean age: 19.82 years; 101 (67.3\%) females; 100 (67\%) Muslim converts) were followed-up prospectively by the Centre de Prévention contre les Dérives Sectaires liées à I'Islam (CPDSI) until September 2016. Using a multiple correspondence analysis, we found that eight motivational dimensions (interest in violence; feelings of depression, responsibility, uncertainty or loneliness; experience of abuse; issues with sexuality; and poor insight) combining in eight statistical factors drove individuals towards radicalization. At FU, 95(63\%) were no longer radicalized, 21(14\%) were disengaged, 19(13\%) were still radicalized, and 15(10\%) had reached the Islamic State. Univariate and multivariate analyses found some protective factors defining individuals with developmental vulnerabilities that can be encountered in many psychopathologies. In addition, multivariate models showed that worse status at FU was predicted by being married, having married parents, having attempted to radicalize other relatives, and having a close friend or relative imprisoned before radicalization. We conclude that multidimensional efforts to de-radicalize young people are efficient, although a worse prognosis is associated with neighborhood/proximal phenomena. Prevention should target these local/proximal contexts to further prevent radicalization.
\end{abstract}

\footnotetext{
${ }^{1}$ Service de Psychiatrie de I'Enfant et de I'Adolescent, APHP, Hôpital Pitié-Salpêtrière, Paris, France. ${ }^{2}$ ARTEMIS, Atelier de Recherche, Traitement et Médiation Interculturelle et Sociale, Paris, France. ${ }^{3}$ Laboratoire PCPP- EA 4056, Institut de Psychologie, Université Paris V René Descartes SPC, Paris, France. ${ }^{4}$ CDPSI and Bouzar-Expertises, Paris, France. ${ }^{5}$ CMPPD, Conseil Départemental des Bouches-du-Rhône, 45 avenue du Prado, 13006 Marseille, France. ${ }^{6}$ Laboratoire de Santé Publique, EA3279, Aix Marseille Université, 27 bd Jean Moulin, 13005 Marseille, France. ${ }^{7}$ EA 7479, SPURBO, 22 avenue Camille Desmoulins, 29200 Brest, France. ${ }^{8}$ Institut des Systèmes Intelligents et de Robotiques, Sorbonne Université, Paris, France. Correspondence and requests for materials should be addressed to N.C. (email: campelo.nicolas@gmail.com)
} 


\section{Introduction}

he terrorism threat level in Europe is critical (Reardon, 2015). The terrorist movements of the 1990s (i.e., AlQaida, Chechen terrorism) aimed to target a foreign country or were fighting for national liberation (Sageman, 2004). Among terrorists, two profiles were highlighted: (1) individuals who commit violent actions within a radical group and (2) individuals - so-called 'lone wolves' - who act in a more isolated manner and radicalize more quickly (Corner and Gill, 2015). This bi-profile model has been questioned by several authors who have shown that leftist extremists and Jihadists are less likely to act as 'lone wolves' compared to other extremists (Chermak et al. 2010). In addition, the most violent 'lone wolves' attacks were conducted by far-right extremists (Bates, 2012; Michael, 2012). Also, because of the decentralized organization of modern jihadist groups, terrorist attacks may sometimes seem committed by isolated actors while they are in fact always linked with a third person, whether this link is physical or virtual (Khosrokhavar, 2014, Kepel, 2016). Therefore, the concept itself of 'lones wolves' does not seem appropriate for radicalized population. Several theoretical models rather describe radicalization as a step-by-step process that may finally lead to a violent form of action directly linked to an extremist ideology (Doosje et al. 2016; Kruglanski et al. 2013, 2014; Moghaddam, 2005; Wiktorowicz, 2005). These models point out the complexity and entanglement of several risk factors (individuals, organizational, environmental and societal) that interact during the radicalization process (Campelo et al. 2018). Individual risk factors of bullying or discrimination such as perceived injustice or feeling of injustice often act as a starting point.

Since the 2010s, a new model of radicalization has appeared in Europe with the increase of 'homegrown' terrorists who remained marginal until then. Born and raised in Europe, these individuals adopt the ideology of violent radical Islamism (Doosje et al. 2016; Khosrokhavar, 2014; McGilloway et al. 2015; O’Duffy, 2008). This transition has created community tensions and animated public debate (Horton, 2016). Today's radical groups are smaller groups, more discrete, and younger and are composed of more fragile individuals who have been influenced by recruiters and who eventually converted to Islam (Khosrokhavar, 2014; Reardon, 2015). Compared to previous organizations such as Al-Qaida that had internal rules based on orders, hierarchy and political agenda corresponding to a pyramidal model, the increasing use of the Internet by jihadist movements since the 2000 s has led to an organizational change: today's radical groups are less organized and less centralized (Kepel, 2016; Nesser, 2008) (Kepel, 2016; Nesser, 2008; Sageman, 2008). The reasons of these changes are multiple and complex, with a combination of geopolitical, religious factors and societal factors. The mutations of modern societies could contribute to the emergence of the phenomenon of radicalization. Bauman evokes a "liquid modernity" where the individual is integrated only by his consumerism (Bauman, 2003). These changes bring along freedom but also some uncertainties, precariousness and insecurity. Khosrokhavar adds that for these young people who suffer from the 'deliquescence of politics' and the 'dispersion of authority between several parental bodies', radical Islamism offers tangible and reassuring norms carried by unambiguous authority (Khosrokhavar, 2015). For Benslama (2016), the traditional model in which filiation defines the identity of the subject is threatened by a new social model in which each subject must forge its place and its identity. Some people are armed to face this challenge, but those who fail may be tempted by the easier solutions offered by radical ideologies: they attack the society that put them in this situation of insecurity (Benslama, 2016).
These points have led some authors to view this new form of radical engagement as a generational and cultural rupture serving an ideology that includes a nihilistic dimension (Roy, 2016).

Under the influence of Islamic State (IS) propaganda, the number of radicalized individuals has greatly increased since 2014. In May 2015, French Home Office services listed 1704 French people who joined the IS in Syria, returned from Syria, were on their way to Syria or said they want to join the IS. An increase of 300\% between January 2014 and May 2015 was observed (Ciotti and Menucci, 2015). A total of 4011 French individuals were registered for radicalization, including 1017 minors (25\%), 1434 females (35\%), and 1672 (42\%) convert Muslims (Ciotti and Menucci, 2015). To tackle the phenomenon of radicalization among young Europeans, authors have suggested individual risk factors such as personal vulnerabilities (e.g., early experiences of abandonment, perceived injustice, personal uncertainty and perceived group threat) and psychiatric disorders (Bazex et al. 2017; Doosje et al. 2013); micro-environmental risk factors such as family dysfunction and friendships with radicalized individuals (Bazex et al. 2017; MIVILUDES, 2015; Schuurman and Horgan, 2016; Van San et al. 2013); societal risk factors such as geopolitical events, societal polarization and societal changes (Benslama, 2016; Coid et al. 2016; O’Duffy, 2008; Wiktorowicz, 2005); and systemic factors such as an encounter between an individual who is a candidate for becoming radicalized and a recruiter who uses sectarian techniques to isolate and dehumanize the candidate (Bouzar, 2014; MIVILUDES, 2015). However, recent reviews have highlighted that studies with empirical data are limited; they are mainly based on either small samples of males involved in terror attacks or projects (Bazex et al. 2017), i.e., a retrospective design (Veldhuis and Staun, 2009), or Muslim by birth individuals (Kundnani, 2015), making it impossible to generalize the results or to establish causal relations. Additionally, several studies remain at a theoretical level or use a population-based sample that provides only indirect tendencies (Schmid, 2013). Some authors chose to focus on the degree of sympathy towards radicalism and extremist beliefs (Bhui et al. 2014; Bhui et al. 2014; Moyano and Trujillo, 2014). Empirical data regarding females and non-Muslim communities are lacking, as well as longitudinal studies investigating programs for de-radicalization.

Here, we report on the first large prospective sample of young French individuals who aimed to join the IS between 2014 and 2016. Through qualitative and quantitative analyses, we explore their profiles of motivation and the characteristics at baseline that predicted prognosis in terms of de-radicalization at last contact.

\section{Material and methods}

Ethics. The Centre de Prévention contre les Dérives Sectaires liées à l'Islam (CPDSI) was commissioned by the French government to support young people and their families who have been impacted by radicalization. Given the nature of the specific goals (supporting de-radicalization, compulsory declaration to the police, and research), this study was led by a specific Home Office decree directed to all heads of police departments (Ministère de l'Intérieur, circulaire INTA1512017J, 20 May 2015). Contact of the target population with the CPDSI was either direct or free through a national phone number (tel 800) or compulsory after contact with local police or under court petition. When individuals or families contacted the CPDSI freely, they were informed of all its services and responsibilities including compulsory declaration to the local police administration of all radicalized individuals. Consequently, some families and/or individuals were 
not inclined to share all requested information, and the grid (see below) could not be fully informed immediately and for all individuals. Similarly, consent could not be obtained at first contact. However, for the research dataset, individuals (and their parents, in the case of minors) signed a consent form for the anonymous use of the data for research at some point during follow-up (FU).

Design of the study. The current study is a prospective observational and interventional study about a new phenomenon with societal and forensic complexities. The design mixes qualitative and quantitative approaches. Based on case-by-case interactions with CPDSI professionals who were responsible for monitoring these young people, the team collected information by conducting semi-structured individual interviews with the young people and/ or their families or group therapy sessions. In most cases, the CPDSI also had access to the recruit's interactions on social networks, their computers, and/or their phones. Videos that were exchanged during recruitment were also used to better understand the recruit's sensitivity to propaganda. Following a qualitative research method from social anthropology (Pope and Mays, 1995), two authors (LB, DB) first immersed themselves in the data and then conducted a thematic analysis of the information gathered from the sample. This analysis explored the different phases of the radicalization process after having categorized the different reasons for engagement. To a large extent, the intervention of the CPDSI enabled the use of a thematic qualitative analysis. Indeed, accessing the raw data enabled the team to deconstruct each individual pathway, both explicitly and implicitly (from conversations with the recruiters, the videos that they shared with the recruits, and interviews with their relatives).

From the first phase of this qualitative approach, we elaborated a grid listing variables and defined 8 motivational profiles (Bouzar and Martin, 2016; Bouzar, 2017). Table S1 lists the motives that were included in the grid. They were exploring several domains such as depressive feelings (e.g., Did he feel unloved?), suicidal behavior (e.g., Had he attempted suicide?), risk-taking behaviors (e.g., Was he putting himself in danger?), issues with sexuality (e.g., Did he feel guilty over homosexual attraction?), in need of saving the world (e.g., Had he already sacrificed to help his family?), interest in violent behaviors (e.g., Was he fascinated by violence?), in search of a better world (e.g., Did he want to do or did he do humanitarian work?), feeling of injustice (e.g., Did he view the world as an unfair environment?), expression of need for justice (e.g., Did he feel guilty over doing nothing to help the oppressed?), searching for heroism (e.g., Did he think he needed to prove that he is a man?), interest in the army and weapons (e.g., Was he attracted to weapons?), in search of an ideal husband/love (e.g., Has she always idealized romantic relationships, e.g., waiting for Prince Charming?), history of recent loss (e.g., Had he been confronted with the recent death of a loved one?) and history of abuse (e.g., Did she experience sexual abuse or physical abuse?). This grid was completed retrospectively for the first 200 cases and then prospectively for the remaining cases. The dataset was updated with additional information during FU. From these 104 items listing many motives for radicalization that appear to be qualitatively different for males and females, LB and DB proposed to distinguish 8 motivational profiles that they named using mythological metaphors:(1) "Zeus" usually a male interested in violence and showing megalomania; (2) "Para-suicidal" usually an individual showing depression, suicidal behavior and risktaking behaviors; (3) "Savior" usually a male in need of saving the world and in search of a better world; (4) "Daeschland" usually a female in search of a better world and showing feeling of injustice; (5) "Mother Theresa" usually a female in need of saving the world and in search of a better world; (6) "Lancelot" usually a male in need for justice and showing heroism, interest in the army and weapons; (7) "Fortress" usually a male with intense sexual fantasies and activity, fear of sexuality and access to violence; (8) "Sleeping beauty" usually a female in search of an ideal husband/ love, and with a frequent history of abuse (Martin and Bouzar, 2016; Bouzar, 2017.)

Besides the list of motivations for radicalization, we also collected other variables of interest: sociodemographic, individual and family characteristics, police intervention, personal history before radicalization, family history, police history before radicalization, intervention after first contact and status at FU. The list of variables is detailed in Table 1. For status at FU, we distinguished 4 different outcomes: no longer radicalized (youths have renounced the conviction that only divine law can fight the corruption of the world); disengaged (youths have denounced the false propaganda and actions of their former jihadist group, but still dream of a world where "the true Islam" would be applied); still radicalized; and reached the IS or deceased. We considered this last outcome as the worst.

Participants. For the current study, we kept all individuals with less than $5 \%$ of missing data who contacted the CDPSI between January 2014 and December 2015. FU was available until December 2016. A total of 150 individuals were included (mean age: 19.82 years $( \pm 5.28)$ [range:13-40]; $101(67.3 \%)$ females; 100 (67\%) convert Muslims). To assess the representability of the sample, we compared the sociodemographic characteristics of our sample with that of all individuals registered for radicalization from the French Home Office during the same period (Fig. 1). Apparently, we included individuals mainly from the Paris area and South-Eastern France. Additionally, our sample included more females, more individuals who were convert Muslims, and more minors. However, the proportion of individuals who reached Syria or Iraq despite intervention was similar (10\%). The characteristics of the sample are summarized in Table 1.

Statistical analysis. We performed two different analyses. First, we aimed to explore whether the 8 motive profiles that were obtained through a qualitative approach (Bouzar and Martin, 2016; Bouzar, 2017) could be confirmed via a quantitative approach. To do so, we conducted a multiple correspondence analysis (MCA) using the 104 motive items (see Table S1). MCA is a statistical method of data reduction that can be used as an equivalent to Principal Component Analysis (PCA) when a dataset has categorical variables. Each motive item was coded as yes (present) or no (absent) in the dataset. The optimal number of statistical factors (i.e., the lowest number of factors still explaining a good percentage of the variability of the data) was determined by visual inspection of the MCA scree plot. Given MCA requirements, the analysis was performed on only individuals with full data available $(N=122)$. For each individual, a main statistical factor (of the 8 statistical factors, the one for which the percentage of individual contribution is maximal) was attributed based on the MCA analyses. Dimensions obtained by the qualitative approach and dimensions obtained by the statistical approach were then compared using the $\mathrm{chi}^{2}$ test.

We then conducted univariate and multivariate analysis to explore prognosis at $\mathrm{FU}$. We created an ordinal prognosis variable with 4 states ranging from best outcome to worst outcome $(4=$ no longer radicalized $>3=$ disengaged $>2=$ still radicalized $>1=$ reached the IS or deceased) and conducted univariate analysis. Then, multivariate models were run using proportional odds ordinal logistic regression. In order to select the explanatory variables, we first used literature/domain knowledge to remove 
Table 1 Characteristics of the adolescents and young adults who were engaged in radicalization $(N=150)$

SOCIODEMOGRAPHICS

Age at first contact, mean (SD) [range] $19.82(5.28)$ [13-40] years Gender, N (\%)

District, $N(\%)$

Socioeconomic status, $N(\%)$

Female: $101(67.3 \%)$

Male: 49 (32.67\%)

Paris area: 65 (43.3\%)

Other: $85(56.7 \%)$

High: $10(6.7 \%)$

Middle: 95 (63.3)

Low: 45 (30\%)

REASONS FOR POLICE REGISTRATION IN THE RADICALIZATION DATABASE

Police arrest for an attempt to reach the 101 (68\%)

IS, N (\%)

Connection on the internet and on social 29 (19\%)

networks, $N(\%)$

Police arrest for preparation of a terror $11(7 \%)$

attack, $N(\%)$

Police arrest for return from Syria, N (\%) $7(5 \%)$

Break with society, $N(\%) \quad 2(1 \%)$

INDIVIDUAL CHARACTERISTICS

\begin{tabular}{ll}
\hline Marital status, N (\%) & Married: $41(27.3 \%)$ \\
& Single: $109(72.7 \%)$ \\
Having a child or more, N (\%) & $32(21.3 \%)$ \\
FAMILY CHARACTERISTICS &
\end{tabular}

Marital status of the parents Married: 66 (44\%)

Divorced or widow: 84

(56\%)

Migration background

No migration: 62 (41.3\%)

North Africa/Middle-East:

51 (34\%)

Africa: 9 (6\%)

Europe (except France): 16

(10.7\%)

French West Indies: 5

(3.3\%)

South-America: 1 (0.7\%)

Double origin: 6 (4\%)

Religious background ${ }^{a} \quad$ No religion: 59 (39\%)

Muslim background: 56

(37.3\%)

Christian background: 102

(68\%)

Other: $10(6.67 \%)$

PERSONAL HISTORY BEFORE RADICALIZATION

\begin{tabular}{|c|c|}
\hline \multicolumn{2}{|l|}{$\begin{array}{l}\text { Suicidal behavior or non-suicidal self-harm } \\
\text { (e.g., scraping), } N(\%)\end{array}$} \\
\hline Psychiatric consultation, N (\%) & $55(35.3 \%)$ \\
\hline Psychiatric hospitalization & $19(12.7 \%)$ \\
\hline Physical health issue, $N(\%)$ & $28(18.7 \%)$ \\
\hline Depressive symptoms, $N(\%)$ & $66(44 \%)$ \\
\hline Addiction and drug abuse, $N(\%)$ & $33(22 \%)$ \\
\hline Fusional relation with one relative, $N(\%)$ & $90(60 \%)$ \\
\hline Dominated by one relative, $N(\%)$ & $69(46 \%)$ \\
\hline $\begin{array}{l}\text { Attempted to radicalize other family } \\
\text { members or friends, } N(\%)\end{array}$ & $57(38 \%)$ \\
\hline Abandonment, $N(\%)$ & $123(82 \%)$ \\
\hline Physical and/or sexual abuse, N (\%) & $41(27 \%)$ \\
\hline Neglect or psychological abuse, N (\%) & $128(85 \%)$ \\
\hline FAMILY HISTORY BEFORE RADICALIZATION & \\
\hline $\begin{array}{l}\text { Previous radicalization in the family, } N \\
(\%)\end{array}$ & $65(43 \%)$ \\
\hline Physical health issue of a relative, $N(\%)$ & $41(27.3 \%)$ \\
\hline Depression in a relative, $N(\%)$ & $61(40.7 \%)$ \\
\hline Rape or abuse, $N(\%)$ & $24(16 \%)$ \\
\hline Physical abuse, N (\%) & $48(32 \%)$ \\
\hline Addiction and drug abuse, $N(\%)$ & $48(32 \%)$ \\
\hline Death of a relative, $N(\%)$ & $(\%)$ \\
\hline
\end{tabular}

unimportant variables and force key variables into the model. We then calculated the maximum number of explanatory variables we could use before overfitting occurs by taking $1 / 10$ th of the limiting sample size. If too many variables remained, we used a stepwise method (R step function) to perform selection among the remaining ones. Criterion of choice was Akaike information criterion (AIC) and the selection was done in both directions. The proportionality assumption was when possible tested using Brant's method (Brant, 1990) or assessed by running separate binary logistic regressions (one for each cut-off of the outcome). We present 2 models to predict prognosis at FU: in the first model, the explanatory variables are all the variables collected in Table 1; in the second model, the explanatory variables are the dimensions defined through MCA.

\section{Results}

MCA of motives for radicalization. Visual inspection of the MCA screen plot (Fig. 2) suggested that increasing beyond 8 dimensions would not improve the variance explained by the MCA. Therefore, we entered an 8-category factorization in the MCA performed on the motives for radicalization. The item-byitem responses (yes in green, no in red) with their contributing scores are detailed in Table S1. Based on the contributing items, we summarize the different statistical factors in Table 2: (F1) violence and megalomania; (F2) depressive symptoms and abuse; (F3) responsibility and guilt; (F4) loneliness and poor insight; (F5) responsibility and sacrifice; (F6) violence and uncertainty; (F7) issues with sexuality; and (F8) loneliness and sensitivity. Interestingly, some themes (groups of related items) are present in several statistical factors: violence, depressive symptoms, the experience of abuse, issues with sexuality, loneliness, an interest in death and responsibility. Table S2 (supplementary material) shows the dimensional correspondences between the qualitative (Bouzar, 2017) and quantitative (or MCA) analyses of the 'grid for radicalization motives'. The qualitative analysis and the quantitative factorizations were significantly related $\left(\chi^{2}=150.99\right.$, $p=.0005)$

Prognosis at FU. At last contact with the CDPSI (Table 1), the mean age was $21.8( \pm 5.4)[15-42]$ years. A total of $95(63 \%)$ individuals were no longer radicalized, $21(14 \%)$ were disengaged, 19 (13\%) were still radicalized, and $15(10 \%)$ (including 3 who were deceased) had reached the IS (Fig. 3). However, despite a high proportion of individuals who had recently converted to Islam and who were no longer radicalized, 138 (92\%) were still Muslim at last contact.

The variables listed in Table 1 that significantly predicted status at FU using univariate analysis are shown in Table 3. Being a female, having parents who were divorced or one parent who had died, having experienced suicidality before radicalization, receiving psychiatric consultation before radicalization and receiving educational and psychiatric monitoring after radicalization were associated with a better outcome at FU. In contrast, being married, having a child, belonging to a family with married parents, having attempted to radicalize other family members or friends, having a close friend or relative imprisoned before radicalization, and being Muslim by birth were associated with a worse outcome. Obviously, the variable 'Muslim by birth' needs to be understood in the context of this sample of radicalized individuals and not generalize to any individuals Muslim by birth.

The multivariate model (ordinal logistic regression, Table 4) produces rather similar findings although few significant variables with univariate analysis where not maintained in the multivariate model (having a child, receiving psychiatric consultation before radicalization and receiving educational and psychiatric 
Table 1 (continued)

POLICE HISTORY BEFORE RADICALIZATION

Educational and social monitoring, N (\%) $33(22 \%)$

Imprisonment of a close friend or relative, $24(16 \%)$

$N(\%)$

Web contact with radicalized individuals, 149 (99\%)

$N(\%)$

Direct contact with radicalized individuals, $84(56 \%)$

$N(\%)$

WHAT HAPPENED AFTER AWARENESS OF RADICALIZATION

Age at last contact with the CPDSI, mean 21.8 (5.4) [15-42] years

(SD) [range]

Police surveillance $139(93 \%)$

House arrest with monitoring $24(16 \%)$

Prosecutor inquiry $58(39 \%)$

Confiscation of identity documents $42(28 \%)$

Justice, educational and social monitoring, 61 (41\%)

$N(\%)$

Educational and psychiatric monitoring $64(43 \%)$

Still Muslim at last contact

$138(92 \%)$

Status at last contact

No longer radicalized: 95 (63\%)

Disengaged: 21 (14\%)

Still radicalized: $19(13 \%)$

Reached the IS: 12 (8\%)

Deceased: 3 (2\%)

aFor religious background, $N$ is $>150$ because father and mother backgrounds differed in several families monitoring after radicalization) whereas few novel variables appeared to be statistically robust. The multivariate model included 4 protective factors significantly associated with a better outcome (positive $\beta$ value and Odd Ratio $>1$ ): age at first contact, fusional relation with one relative, physical health issue with a relative, and having experienced suicidality before radicalization; and 7 risk factors significantly associated with a worse outcome (negative $\beta$ value and Odd Ratio $<1$ ): being male, being married, belonging to a family with married parents, being Muslim by birth, attempting to have radicalized other relatives, having a close friend or relative imprisoned before radicalization and having experienced the death of a relative before radicalization.

Regarding the 8 statistical factors from the MCA (Table 2), multivariate analysis to predict status at $\mathrm{FU}$ (Table 5) showed that

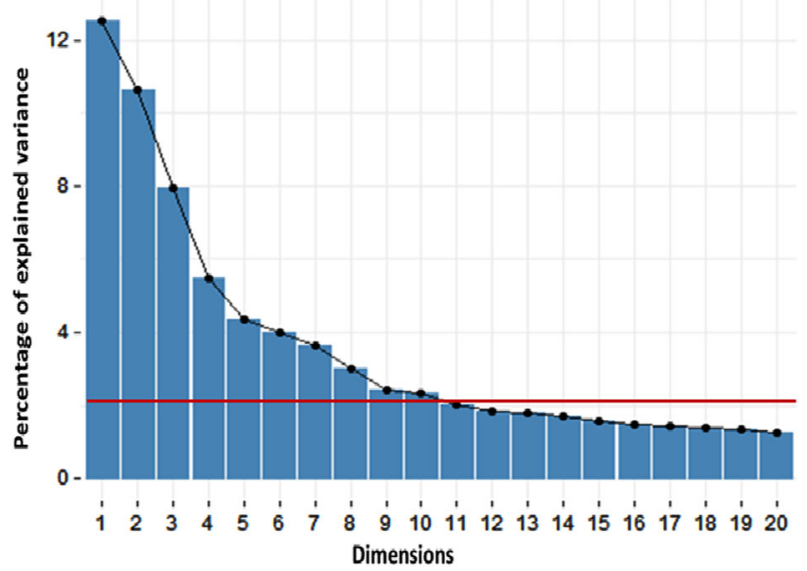

Fig. 2 Scree plot of the multiple correspondence analysis applied to motives for radicalization $(N=122)$
Individuals registered for radicalization in the French national database from April 2014 and May 2015

( $N=4091$ ) (from Ciottiand Menucci, 2015)

\section{CPDSI sample from January 2014 to December $2016(\mathrm{~N}=150)$}

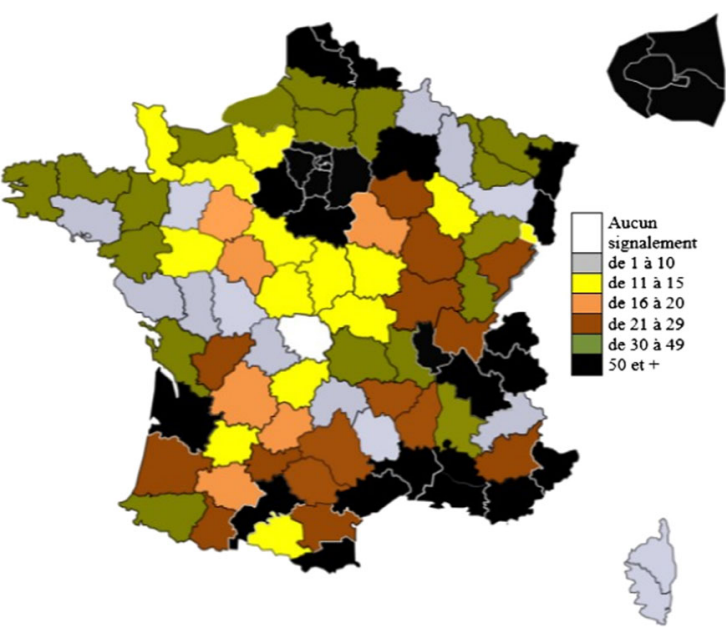

$3074(75 \%) \geq 18$ years vs. $1017(25 \%)<18$ years

2657 (65\%) males vs. 1434 (35\%) females

2419 (59\%) Muslim by birth vs. 1672 (41\%) convert Muslims $368(9 \%)$ located in Iraq or Syria

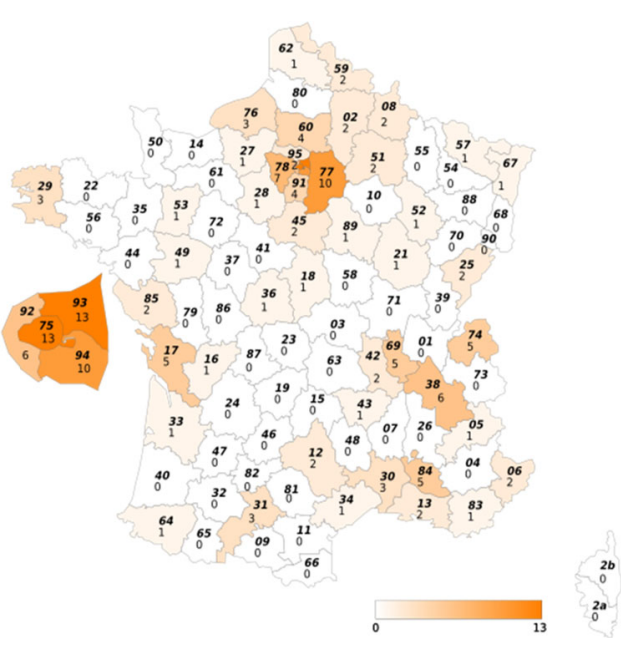

$81(54 \%) \geq 18$ years vs. $69(46 \%)<18$ years

$49(33 \%)$ males vs. $101(67 \%)$ females

$50(33 \%)$ Muslim by birth vs. $100(67 \%)$ converts Muslims $15(10 \%)$ located in Iraq or Syria

Fig. 1 Sociodemographic characteristics of the individuals registered for radicalization from the French Home Office (Ministère de l'Intérieur: Unité de coordination de lutte anti-terroriste, UCLAT) and comparison with the Centre for the Prevention of Islamic Sectoral Derivatives (CPDSI) sample 


\section{Table 2 Motives for radicalization in French young people based on a multiple correspondence analysis $(N=122):$ description of} the 8 dimensions

Violence and megalomania

Depressive symptoms and abuse Responsibility and guilt

Loneliness and poor insight

Responsibility and sacrifice

Violence and uncertainty

Sexuality content

Loneliness and sensitivity
Individuals report violence, an interest in weapons, adventure, fighting, 'male values', no lack of self-esteem, no search for tenderness

Individuals report depressive feelings, risk-taking behaviors, suicidal behavior, a frequent history of abuse Individuals report feelings of responsibility and guilt for others and relatives, fear of hell, a frequent history of a relative in pain

Individuals report expression of loneliness, no interest in others, resignation

Individuals report feelings of responsibility and guilt, expression of being evil, fear of sexuality, suicidal behavior and an interest in death, expression of sacrifice

Individuals report violence, an interest in weapons, fighting, the army, homosexual feelings, expression of difficulties in interacting with people, but altruism

Intense sexual fantasies and activity, feeling of guilt when happy, no search for protection or in-group belonging, a frequent history of abuse

Expression of loneliness, no territory, feelings of persecution, identification with 'oppressed peoples', suicidal behavior and an interest in death only the first factor (F1: violence and megalomania) was marginally associated with a worse outcome $(\beta=-.25, p$ $=.075)$. We ran the same model using the qualitative dimensions (Bouzar, 2017). Two dimensions were significantly associated with a worse outcome: "Zeus" and "Lancelot" (Table 6). Interestingly, individuals with these motivational dimensions exhibited megalomania and violence and were interested in heroism, weapons, and military activities.

\section{Discussion}

Radicalization in European countries appears to be a complex phenomenon. Our approach, combining qualitative and quantitative methods, delineated a large combination of motives defining 8 statistical factors: (F1) violence and megalomania; (F2) depressive symptoms and abuse; (F3) responsibility and guilt; (F4) loneliness and poor insight; (F5) responsibility and sacrifice; (F6) violence and uncertainty; (F7) issues with sexuality; and (F8) loneliness and sensitivity. Interestingly, some themes describing both external (e.g., violence, loneliness) and internal (depressive symptoms, issues with sexuality, an interest in death and feelings of responsibility or of uncertainty) behaviors were present in several statistical factors. In addition, a history of abuse appeared to be a contributing experience. Some of these vulnerabilities have been cited in the literature but mainly in qualitative or case studies: depression (Bazex and Mensat, 2016; Bhui et al. 2014; Rolling and Corduan, 2017), uncertainty (Doosje et al. 2013), guilt (Dayan, 2015), a history of abuse (Rolling and Corduan, 2017), and an interest in weapons and violence (Sageman, 2004). However, factorization showed that these themes defining 8 dimensions act in combination rather than alone, re-enforcing the complexity and diversity of the motivation profiles. Issues with sexuality have not been described except in the qualitative categorization provided by Bouzar and Martin (Bouzar and Martin, 2016). However, the press has already noted some contradictory behaviors in a few terrorists who claimed responsibility for acts of terror under the rules of radical Islamism but had uncontrolled sexual hyperactivity before acting out (this profile seems to be the profile of Mohamed Lahouaiej-Bouhlel, who committed the Nice terror attack on 13 July 2016). The qualitative analysis that preceded the current study (Bouzar, 2017) and the quantitative factorizations were significantly related, showing the validity of the qualitative approach. Four statistical factors were similar, and four were different but had similar themes. We believe that the differences were related to the inclusion of gender with regard to how the qualitative classification was performed (see supplementary Table S2 and previous studies;(Bouzar and Martin, 2016; Bouzar, 2017)). In terms of prediction, only factor
F1 (violence and megalomania) was marginally associated with a worse outcome Table 5 and 6.

Regarding prognosis at FU, the current study is encouraging to some extent. Although 34 (23\%) individuals had reached the IS or were still radicalized at FU, $116(77 \%)$ individuals were no longer radicalized or were disengaged. This finding highlights that interventions after first contact that were adjudicated after caseby-case analysis had some protective effects, either they were measures adjudicated by law (police surveillance, house arrest with monitoring, prosecutor inquiry, confiscation of identity documents) or they were proposed by specialized services (justice educational and social monitoring, educational and psychiatric monitoring). Univariate analysis delineated the following protective factors: 'being a female', 'having parents who were divorced or one parent who had died', 'having experienced suicidality before radicalization', 'receiving psychiatric consultation before radicalization' and 'receiving educational and psychiatric monitoring after radicalization'. These protective factors define individuals with developmental vulnerabilities that are not specific to radicalization but can be encountered in many psychopathologies (Cohen, 2010; Poulton et al. 2002). It is likely that the support received by these vulnerable individuals had a positive impact on FU (Bouzar, 2017). The multivariate model found that several vulnerabilities to psychopathology (fusional relation with one relative, physical health issue with a relative, and having experienced suicidality before radicalization) were indeed protective factor in this sample. We formulate the hypothesis according to which for the young people who had these vulnerabilities related to attachment problems or experience of loss, the radical commitment was particularly linked to this negative experience. The way out from the radical commitment was therefore favored by the psychiatric, psychological and/or educational care since the psychological vulnerabilities at the origin of the engagement were taken care of. This hypothesis highlights the importance of psychiatric, psychological and/or educational care, especially for those young people who have experienced life adversities (Campelo et al., 2018).

In the multivariate models, they were several risk factors and some were somewhat challenging to interpret at first glance. We found that 'being male', 'being Muslim by birth', 'being married', 'belonging to a family with married parents', 'having attempted to radicalize other relatives', and 'having a relative or close friend imprisoned before radicalization', and 'having experienced the death of a relative before radicalization' had a negative impact on outcome. Being male, being Muslim by birth or having a history of imprisoned relatives or friends make sense in terms of the known association between violence and radical Islamism 


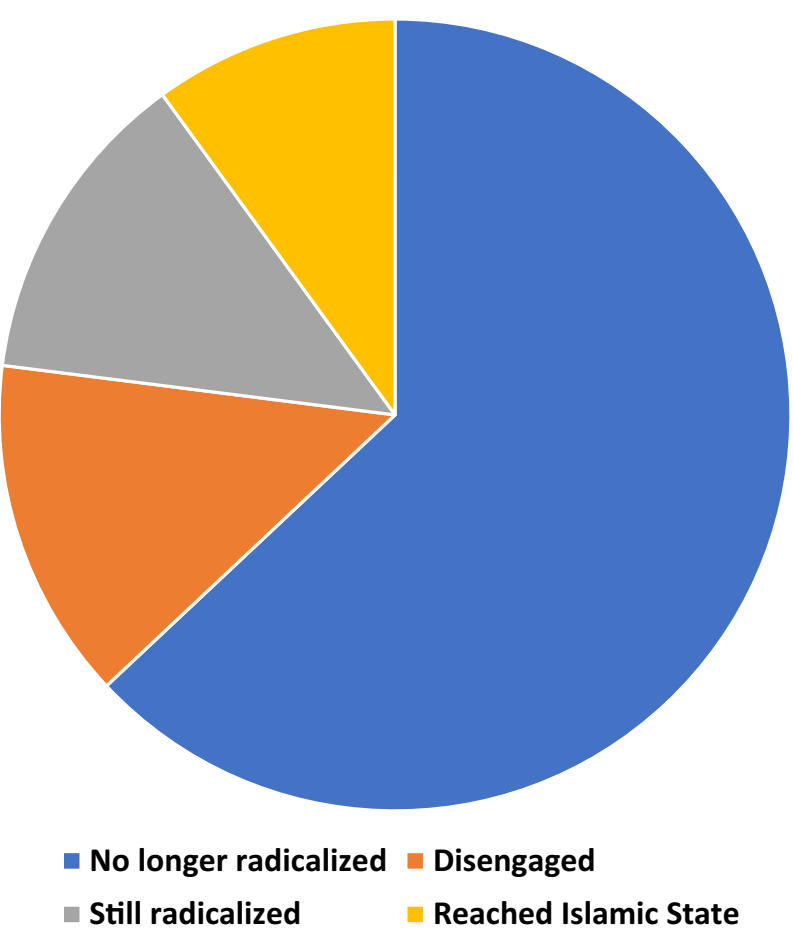

Fig. 3 Pie diagram of individuals' outcomes

(Reardon, 2015) and also in terms of violence and an interest in weapons, as claimed repeatedly (Bouzar and Martin, 2016; Sageman, 2004). Indeed, males who had an imprisoned relative or friend are more likely to exhibit antisocial behavior in their adolescence or adulthood. Children separated from a parent for other motives do not show the same level of antisocial outcome severity (Murray and Farrington, 2005). Also, having experienced the death of a relative before radicalization may be associated with the feeling that one's has nothing more to lose defining a more desperate profile. We believe that this experience of loss is not opposed to the protective factors that were discussed previously if one accept the idea that in some cases vulnerabilities are just too much too handle for some individuals. However, the 3 other risk factors are not easy to understand. Regarding the 'being married' factor, we believe that in the context of radicalized couples, the husband supports his wife's commitment to radicalization and vice versa. The dyadic relationship within the couple acts as a cement that amplifies adhesion to the radical ideology. It may also increase the splitting with previous friends and nonradicalized relatives, and the feeling of being involved in something meaningful (Khosrokhavar, 2014; Bouzar, 2014). The 'belonging to a family with married parents' factor (together with being Muslim by birth) can also illustrate that radicalization may be promoted in stable Islamic families through education and also through belonging to Islamic communities in which some individuals already experienced radicalization. Indeed, the fact that 'trying to have radicalized other relatives' is also a risk factor may be the reverse proposal and the evidence that most extreme radicalized individuals have tried to motivate other relatives to join their cause (Schuurman and Horgan, 2016; Van San et al. 2013). Again, as stated previously, the variable 'Muslim by birth' needs to be understood in the context of this sample of radicalized individuals and not generalize to any individuals Muslim by birth.

In a more general view, we hypothesized that these factors were related to neighborhood/proximal phenomena. To verify this interpretation, we returned to the individual data and found that

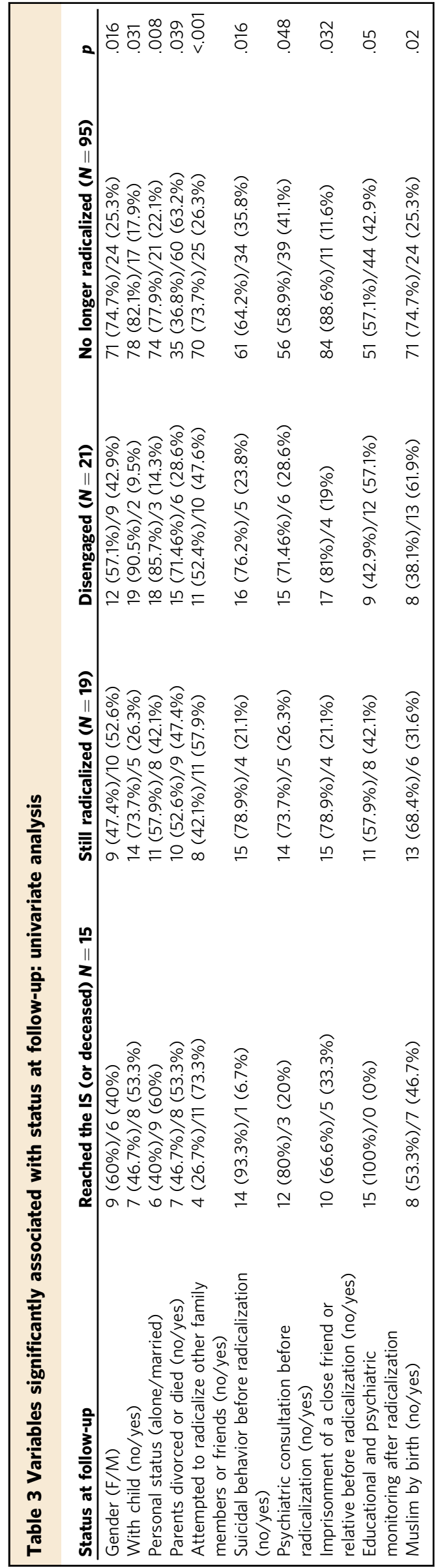


Table 4 Ordinal logistic regression analysis: status at follow-up according to variables present in Table 1

Age at first contact

Being Muslim by birth (yes vs. no)

Belonging to a family with married parents (yes vs. no)

Marital status (married: yes vs. no)

Having attempted to radicalize others (yes vs. no)

Experiencing suicidality before radicalization (yes vs. no)

Imprisonment of a close friend or relative before radicalization (yes vs. no)

Fusional relation with one relative (yes vs. no)

Physical health issue of a relative (yes vs. no)

Death of a relative (yes vs. no)

Reached the IS vs. still radicalized/disengaged/no longer radicalized

Reached the IS/still radicalized vs. disengaged/no longer radicalized

Reached the IS/still radicalized/disengaged vs. no longer radicalized

IS Islamic State

\begin{tabular}{lllll} 
B estimate & Odd ratio & Standard error & $\boldsymbol{t}$-value & $\boldsymbol{p}$-value \\
\hline-1.17 & 0.31 & 0.47 & -1.8685 & 0.014 \\
0.15 & 1.16 & 0.05 & 3.08 & 0.002 \\
-1.25 & 0.29 & 0.4 & -3.11 & 0.002 \\
-1.26 & 0.28 & 0.43 & -2.97 & 0.004 \\
-2 & 0.13 & 0.54 & -3.7 & $<0.001$ \\
-1.81 & 0.16 & 0.47 & -3.85 & $<0.001$ \\
1.33 & 3.77 & 0.52 & 2.54 & 0.012 \\
-1.88 & 0.15 & 0.54 & -3.47 & 0.001 \\
0.84 & 2.32 & 0.42 & 2.02 & 0.045 \\
1.33 & 3.78 & 0.51 & 2.58 & 0.011 \\
-1.11 & 0.33 & 0.44 & -2.52 & 0.013 \\
-2.4 & & 1.02 & -2.35 & 0.012 \\
-1.12 & & 0.99 & -1.13 & $>0.05$ \\
-0.13 & & 0.99 & -0.13 & $>0.05$ \\
\hline
\end{tabular}

Table 5 Ordinal logistic regression analysis: status at follow-up according to quantitative (MCA) motivational dimensions

\begin{tabular}{|c|c|c|c|c|}
\hline Factor 2: Depression and abuse & 0.069 & 0.191 & 0.3621 & 0.717 \\
\hline Factor 4: Loneliness and poor insight & 0.109 & 0.215 & 0.5063 & 0.613 \\
\hline Factor 5: Responsibility and sacrifice & 0.208 & 0.241 & 0.8637 & 0.388 \\
\hline Factor 6: Violence and uncertainty & -0.080 & 0.182 & -0.4390 & 0.661 \\
\hline Factor 7: Issue with sexuality & 0.126 & 0.182 & 0.6939 & 0.488 \\
\hline Reached the IS/still radicalized vs. disengaged/no longer radicalized & -1.661 & 0.503 & -3.2993 & $<0.001$ \\
\hline Reached the IS/still radicalized/disengaged vs. no longer radicalized & -0.989 & 0.480 & -2.0602 & 0.039 \\
\hline
\end{tabular}

Table 6 Ordinal logistic regression analysis: status at follow-up according to qualitative motivational dimensions

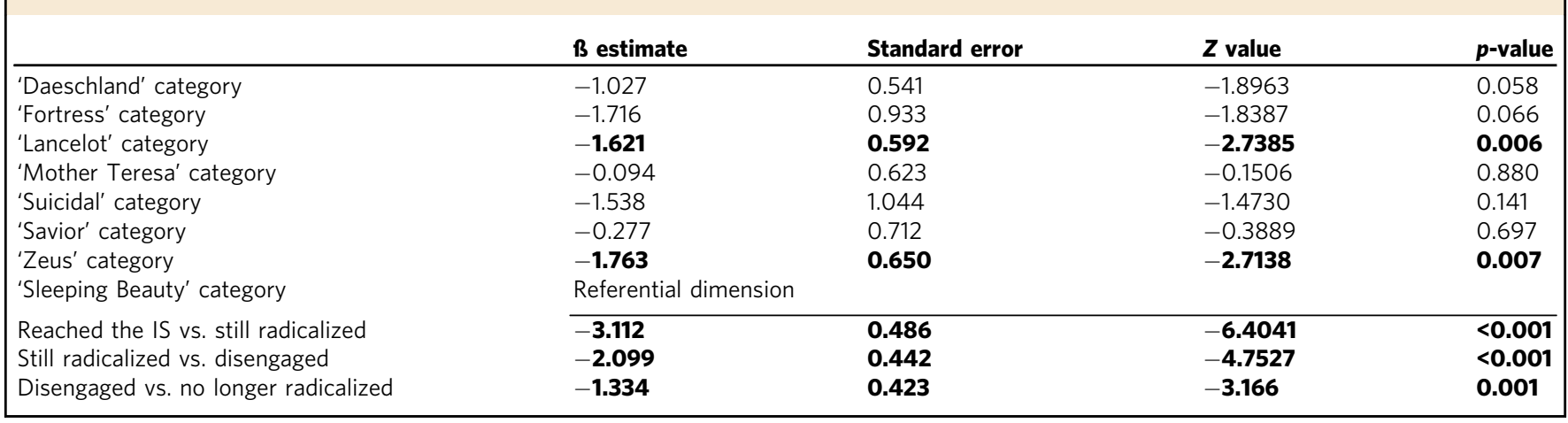

a high proportion of the 15 individuals who had reached the IS came from the Paris area $(N=9,60 \%)$ and had moved (or tried to move) to a zone with a friend, a relative or a family $(N=11$, $73 \%$ ). These proximal phenomena have been highlighted by French intelligence services since it appears that repartition of radicalization is not equally distributed (see the 2015 map in Fig. 1) and is more frequent in prison (Ciotti and Menucci, 2015). Therefore, imprisonment may be understood not only as a factor associated with delinquency but also as a factor in which proximal phenomena may occur.
We are aware that this study has limitations. First, systematic declaration to the police may have altered the authenticity of some information, and we believe that keeping cases with only $5 \%$ of missing data facilitated analyzing the best informative cases. Second, some limitations are related to the sample itself. As explained in the method section, the sample included more females, adolescents and convert Muslims than the current known distribution of radicalized individuals in France (see Fig. 1). We believe that in our sample, families showed more concern regarding these individuals, as radicalism appeared to be 
dramatically opposed to their beliefs and background. Nevertheless, we had the same proportion of individuals who reached the IS, and proximal risk factors were captured in the multivariate model.

\section{Conclusion}

We conclude that radicalization in European countries appears to be a complex phenomenon and that young people who go through the process of radicalization have very different profiles and motives. It is therefore crucial not to apply a simplistic model of understanding, as well as a unique model of care for these young people with different profiles and motivations. Future research may help to refine the understanding and the ways to cope with this diversity. Meanwhile, it seems essential to remain attentive to the specificities of each radicalized subject and to adapt to each situation. Multidimensional efforts to de-radicalize young people are efficient for vulnerable young individuals that have experienced loss or needed psychological care in the past. Beyond the repressive and security apparatus, educational accompaniment and systematic psychological care could favor the chances for the subject to leave the radical process and to reintegrate society. However, a worse prognosis is associated with neighborhood/proximal phenomena and a history of violence. Therefore, politics and public health actions should target specifically these local/proximal contexts to further prevent radicalization.

Received: 12 May 2018 Accepted: 2 October 2018

Published online: 14 November 2018

\section{References}

Bates R (2012) Dancing With Wolves: Today's Lone Wolf Terrorists. J Public Profession Sociol 4(1) https://digitalcommons.kennesaw.edu/jpps/vol4/iss1/1 Bauman Z (2003) Vivre dans la modernité liquide. Faculté des Sciences Sociales, Strasbourg

Bazex H, Mensat J-Y (2016) Qui sont les djihadistes français? Analyse de 12 cas pour contribuer à l'élaboration de profils et à l'évaluation du risque de passage à l'acte. Ann Médico-Psychol, Rev Psychiatr 174:257-265

Bazex H, Bénézech M, Mensat J-Y (2017) « Le miroir de la haine ». La prise en charge pénitentiaire de la radicalisation : analyse clinique et criminologique de 112 personnes placées sous main de justice. Ann Médico-Psychol, Rev Psychiatr 175(3):276-282. https://doi.org/10.1016/j.amp.2017.01.009

Benslama F (2016) Un furieux désir de sacrifice, le surmusulman. Seuil. http://www. seuil.com/ouvrage/un-furieux-desir-de-sacrifice-le-surmusulman-fethibenslama/9782021319095 Accessed 25 Nov 2017

Bhui K, Warfa N, Jones E (2014) Is Violent Radicalisation Associated with Poverty, Migration, Poor Self-Reported Health and Common Mental Disorders? PLOS ONE 9(3):e90718. https://doi.org/10.1371/journal.pone.0090718

Bhui K, Everitt B, Jones E (2014) Might Depression, Psychosocial Adversity, and Limited Social Assets Explain Vulnerability to and Resistance against Violent Radicalisation? PLOS ONE 9(9):e105918. https://doi.org/10.1371/journal. pone. 0105918

Bouzar D (2014) La mutation du discours djihadiste: les nouvelles formes de radicalisme musulman. In: Cahiers de la Sécurité et de la Justice - La Radicalisation Violente. La Documentation Française, Paris

Bouzar D (2017) A Novel Motivation-based Conceptual Framework for Disengagement and De-radicalization Programs. Sociol Anthropol 5(8):600-614. https://doi.org/10.13189/sa.2017.050804

Bouzar D, Martin M (2016) Pour quels motifs les jeunes s'engagent-ils dans le djihad ? Neuropsychiatr De l'Enfance Et De l'Adolescence 64(6):353-359. https://doi.org/10.1016/j.neurenf.2016.08.002

Brant R (1990) Assessing proportionality in the proportional odds model for ordinal logistic regression. Biometrics 46(4):1171-1178

Campelo N, Oppetit A, Neau F, Cohen D, Bronsard G. (2018) Who are the youths willing to join the IslamicState? A multidisciplinary review. European Psychiatry $52: 1-14$

Chermak SM, Freilich JD, JR JS (2010) Surveying American State Police Agencies About Lone Wolves, Far-Right Criminality, and Far-Right and Islamic
Jihadist Criminal Collaboration. Stud Confl \& Terror 33(11):1019-1041. https://doi.org/10.1080/1057610X.2010.514698

Ciotti E, Menucci R (2015) No 2828 - Rapport d'enquête de M. Patrick Mennucci sur la surveillance des filières et des individus djihadistes. Assemblée Nationale Française. http://www.assemblee-nationale.fr/14/rap-enq/r2828.asp Accessed 28 Jan 2018

Cohen D (2010) Probabilistic epigenesis: An alternative causal model for conduct disorders in children and adolescents. Neurosci Biobehav Rev 34(1):119-129. https://doi.org/10.1016/j.neubiorev.2009.07.011

Coid JW, Bhui K, MacManus D et al. (2016) Extremism, religion and psychiatric morbidity in a population-based sample of young men. Br J Psychiatry 209 (6):491-497. https://doi.org/10.1192/bjp.bp.116.186510

Corner E, Gill P (2015) A false dichotomy? Mental illness and lone-actor terrorism. Law Human Behav 39(1):23-34. https://doi.org/10.1037/lhb0000102

Dayan J (2015) Crimes de haine. Adolescence T 33 n 3(3):613-640. https://doi. org/10.3917/ado.093.0613

Doosje B, Loseman A, van den Bos K (2013) Determinants of Radicalization of Islamic Youth in the Netherlands: Personal Uncertainty, Perceived Injustice, and Perceived Group Threat. J Social Issues 69(3):586-604. https://doi.org/ 10.1111/josi.12030

Doosje B, Moghaddam F, Kruglanski A et al. (2016) Terrorism, radicalization and de-radicalization. Curr Opin Psychol 11:79-84

Horton R (2016) Offline: A physician's response to religious conflict. Lancet 388 (10043):448. https://doi.org/10.1016/S0140-6736(16)31149-7

Kepel G (2016) Terreur dans l'Hexagone, Genèse du djihad français. Gallimard, Paris, http://www.institutmontaigne.org/publications/terreur-dans-lhexagone Accessed 25 Nov 2017

Khosrokhavar F (2014) Radicalisation. Éditions de la Maison des sciences de l'homme, Paris

Khosrokhavar F (2015) Les trajectoires des jeunes jihadistes français. Études juin 6:33-44

Kruglanski AW, Bélanger JJ, Gelfand M et al. (2013) Terrorism--a (self) love story: redirecting the significance quest can end violence. Am Psychol 68 (7):559-575. https://doi.org/10.1037/a0032615

Kruglanski AW, Gelfand MJ, Bélanger JJ et al. (2014) The Psychology of Radicalization and Deradicalization: How Significance Quest Impacts Violent Extremism. Political Psychol 35:69-93. https://doi.org/10.1111/pops.12163

Kundnani A (2015) A Decade Lost: Rethinking Radicalisation and Extremism | Extremism | Islamism. Claystone. http://www.claystone.org.uk/wp-content/ uploads/2015/01/Claystone-rethinkingradicalisation.pdf Accessed 28 Jan 2018

McGilloway A, Ghosh P, Bhui K (2015) A systematic review of pathways to and processes associated with radicalization and extremism amongst Muslims in Western societies. Int Rev Psychiatry 27(1):39-50. https://doi.org/10.3109/ 09540261.2014 .992008

Michael G (2012) Lone wolf terror and the rise of leaderless resistance. Vanderbilt University Press.

MIVILUDES (2015) Mission interministérielle de vigilance et de lutte contre les dérives sectaires. Cabinet du Premier Ministre. http://psy-dignelesbains.fr/ wp-content/uploads/2016/04/Processus-de-radicalisation-et-emprisementale-Version-finale.pdf Accessed 6 December 2017).

Moghaddam FM (2005) The staircase to terrorism: a psychological exploration. Am Psychol 60(2):161-169. https://doi.org/10.1037/0003-066X.60.2.161

Moyano M, Trujillo HM (2014) Intention of activism and radicalism among Muslim and Christian youth in a marginal neighbourhood in a Spanish city $/$ Intención de activismo y radicalismo de jóvenes musulmanes y cristianos residentes en un barrio marginal de una ciudad española. Rev De Psicol Social 29(1):90-120. https://doi.org/10.1080/02134748.2013.878571

Murray J, Farrington DP (2005) Parental imprisonment: effects on boys' antisocial behaviour and delinquency through the life-course. J Child Psychol Psychiatry, Allied Discip 46(12):1269-1278. https://doi.org/10.1111/j.14697610.2005.01433.x

Nesser P (2008) How did Europe's Global Jihadis Obtain Training for their Militant Causes? Terror Political Violence 20(2):234-256. https://doi.org/ $10.1080 / 09546550801920758$

O'Duffy B (2008) Radical Atmosphere: Explaining Jihadist Radicalization in the UK. PS: Political Sci \& Polit 41(1):37-42. https://doi.org/10.1017/ S1049096508080050

Pope C, Mays N (1995) Reaching the parts other methods cannot reach: an introduction to qualitative methods in health and health services research. BMJ : Br Med J 311(6996):42-45

Poulton R, Caspi A, Milne BJ et al. (2002) Association between children's experience of socioeconomic disadvantage and adult health: a life-course study. Lancet 360(9346):1640-1645. https://doi.org/10.1016/S0140-6736(02) $11602-3$

Reardon S (2015) Terrorism: Science seeks roots of terror. Nature 517 (7535):420-421. https://doi.org/10.1038/517420a 
Rolling J, Corduan G (2017) La radicalisation, un nouveau symptôme adolescent? Neuropsychiatrie de l'Enfance et de l'Adolescence. https://doi.org/10.1016/j. neurenf.2017.10.002.

Roy O (2016) Le Djihad et la mort. Seuil, Paris, http://www.seuil.com/ouvrage/ledjihad-et-la-mort-olivier-roy/9782021327045 Accessed 18 Feb 2018

Sageman M (2004) Understanding terror networks. University of Pennsylvania Press, Philadelphia

Sageman M (2008) Leaderless Jihad. In: Terror networks in the twenty-first century. University of Pennsylvania Press, Philadelphia, PA

Schmid DAP (2013) Radicalisation, De-Radicalisation, Counter-Radicalisation: A Conceptual Discussion and Literature Review. https://icct.nl/publication/ radicalisation-de-radicalisation-counter-radicalisation-a-conceptualdiscussion-and-literature-review/ Accessed 28 Jan 2018

Schuurman B, Horgan JG (2016) Rationales for terrorist violence in homegrown jihadist groups: A case study from the Netherlands. Aggress Violent Behav 27 (Supplement C):55-63. https://doi.org/10.1016/j.avb.2016.02.005

Van San M, Sieckelinck S, de Winter M (2013) Ideals adrift: an educational approach to radicalization. Ethics Educ 8(3):276-289. https://doi.org/ $10.1080 / 17449642.2013 .878100$

Veldhuis TM, Staun J (2009) Islamist radicalisation: a root cause model. https:// www.rug.nl/research/portal/publications/islamist-radicalisation-a-rootcause-model(a8629a6e-2c7e-4ae2-81e3-91b4ed1c26cf)/export.html accessed 28 Jan 2018

Wiktorowicz Q (2005) A Genealogy of Radical Islam. Stud Confl Terror 28 (2):75-97. https://doi.org/10.1080/10576100590905057

\section{Data availability}

The datasets generated during and/or analyzed during the current study are not publicly available due to issues concerning individual privacy. However, they are available from the corresponding author on reasonable request.

\section{Acknowledgements}

The study was funded by the French Home Office (Ministère de l'Intérieur, CIPD: Centre international de prévention de la délinquance) and the French Prime Minister Office (MIVILUDES: Mission interministérielle de vigilance et de lutte contre les dérives sectaires). The funding source had no influence on the content, analysis and interpretation of the data.

\section{Author contributions}

: NC, DB, DC, GB designed the study; LB, DB, SH, NC collected the dataset; LB, SH and DB performed the qualitative analysis; DC, AO, and HP performed the quantitative analysis; NC, DB, GB and AO made the literature search; DC, NC, AO and GB drafted the MS; all authors reviewed and approved the MS.

\section{Additional information}

Supplementary information: The online version of this article (https://doi.org/10.1057/ s41599-018-0191-8) contains supplementary material.

Competing interests: LB and DB are currently employees of Bouzar-Expertises, a training firm dedicated to radicalization that offer training session for Justice, Police, Psychiatric and Social Agency staff on the topic of radicalization and radical Islamism. The remaining authors declare no competing interests.

Ethical approval: Ministère de l'Intérieur, circulaire INTA1512017J, 20 May 2015

Reprints and permission information is available online at http://www.nature.com/ reprints

Publisher's note: Springer Nature remains neutral with regard to jurisdictional claims in published maps and institutional affiliations.

\begin{abstract}
(c) (i) Open Access This article is licensed under a Creative Commons BY Attribution 4.0 International License, which permits use, sharing, adaptation, distribution and reproduction in any medium or format, as long as you give appropriate credit to the original author(s) and the source, provide a link to the Creative Commons license, and indicate if changes were made. The images or other third party material in this article are included in the article's Creative Commons license, unless indicated otherwise in a credit line to the material. If material is not included in the article's Creative Commons license and your intended use is not permitted by statutory regulation or exceeds the permitted use, you will need to obtain permission directly from the copyright holder. To view a copy of this license, visit http://creativecommons.org/ licenses/by/4.0/.
\end{abstract}

(C) The Author(s) 2018 